\title{
Effects of Variable Oxygenation and Gradual Withdrawal of Oxygen During the Recovery Phase in Oxygen-Induced Retinopathy: Kitten Model
}

\author{
I)AIE: L. PHEI.PS ANI) ARTHIUR I.. ROSENBAL:M

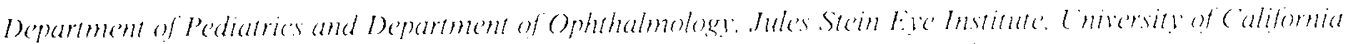

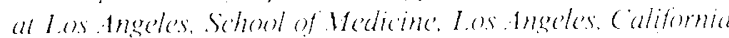

\begin{abstract}
ABSIRACT. The effects of two types of prolonged oxygen supplementation were tested in the kitten model of oxygen induced retinopathy. Thirty-one litters were placed in $80 \%$ oxygen for $65 \mathrm{~h}$ starting the 3rd day after birth to initiate a moderately severe retinopathy. One-half of each litter thereafter served as controls, remaining in room air during the development of the retinopathy. In the remaining half, the retinopathy was allowed to develop in either a variably hyperoxic/hypoxic environment (one-half of each of 16 litters) or in an oxygen environment that was gradually reduced to room air by $4 \mathrm{wk}$ (one-half of each of 15 litters). The retinopathy scores in the controls were comparable in both studies and the same as in previous experience with this model. Kittens exposed to the variable oxygen recovery environment had significantly less severe retinopathy than their room air recovery littermates $(p<0.05)$. The retinopathy scores in the group with gradually withdrawn oxygen did not differ from the littermate controls (power $>\mathbf{8 0} \%$ ). These data support the hypothesis that conditions of oxygenation during the recovery process from an acute oxygen-induced vascular injury have a significant effect on the healing process. (Pediatr Res 22: 297-301, 1987)
\end{abstract}

Abbreviation

ROP, retinopathy of prematurity

ROP is a developmental disorder of the immature retinal vasculature that occurs in a high proportion of the smallest premature infants, up to $85 \%$ in those weighing less than $1 \mathrm{~kg}$ at birth $(1-9)$. This occurs despite the hest current oxygen monitoring capabilities; thus the etiologic role implied by uncontrolled oxygen administration in the 1940)s and 50 s (10) no longer appears applicable. The contribution of oxygen to ROP as seen in the 1980 s is heing seriously reconsidered $(5,11,12)$.

Fortunately ROP heals without sequelae in most infants. however, there is no understanding as to why the remainder progress to retinal scarring and sometimes retinal detachment. We sought a possible explanation by examining recently published nursery surveys and case control studies of severe ROP. They reveal that after controlling for gestational age and/or birth weight (the most important predictors of $\mathrm{R}(\mathrm{OP})$, investigators consistently find that duration of administration of oxvgen (in cxcess of 4 to $6 \mathrm{wk}$ ) is

Reccived February 9.1987: accepted April 9, 1987.

Date I Phelps MD Associate Professor of Pediatrics and Ophthalmologs. Deparment of Pediatrics Box 651 . University of Rochester School of Medicine 601 IImwool Avenuc. Rochester. NY 14642.

Supported by the USPIS. National lye Institute (irant 1:Y 0347.3 the best predictor of severe ROP (5-7). The problem with oxygen administration as an explanator sariable is of course, that it is nonspecific and its profonged administration usually just identifies a particular infant as having a complex. unstable hospital course. Therefore it is not surprising that other significant associations with severe ROP that have been noted are apnea. apnea requiring bagging. sepsis. amount of blood transfused. exchange transfusions, intraventricular hemorrhage. infant of a diabetic mother. twins. elevations in arterial carbon dioxide content. and hyperoxic episodes and hypoxic episodes (5-10, 13. 14). While we believe that these unstable physiologic conditions superimposed on the immature retinal rasculature, lead to the $R() P$, it is unclear to what extent the oxygen supplementation. per se contributes. Howerer. since ischemia is believed to be a major component in the somewhat similat diabetic and sickle cell retinopathies, we questioned whether hypoxemia might be playing a significant role in the progression of R(OP.

When oxven is given to premature infants there is a continuous effort on the part of physicians to discontinue the oxygen in the hope of aroiding pulmonary oxygen toxicity. lowering hospital expense. permitting the infant to be discharged home and it has been believed, to avoid ROP. Whik healthy infants have arterial $\mathrm{Pa}()$, values in the 9()$-100$ torr range. levels of only $40-50$ torr seem to be needed to aroid ststemic hyoxia. The fear of oxygen toxicity has pressured physicians to give just enough oxigen to stay in the lower portion of the range between these two pairs of figures, usually $40-80$ torr (15). (haracteristically then infants receiving oxven supplements generally have lower arterial oxygen levels than normal healthy infants. Based on this realization. we hypothesized that relatively continuous hypoxia or intermittent hypoxia alternating with hyperoxic episodes during a prolonged period of necessary oxygen administrattion might be responsible for acute $R O P$ progressing to the severe form of the discase

We studied this hypothesis in the kitten. oxygen-induced retinopathy model. In this model, initial Pa(), values of around 280 torr $(80 \%$ inspired oxygen) for 65 h initiates a moderately severe retinopathy that develops over the ensuing 2-4 wh. The effects of various oxvgenation levels on the development of that retinopathy during the recovery period can then be studied. In a previously reported investigation. we found that chronic marginal hypoxemia, induced by breathing $13 \%$ oxygen (arterial po). $=39 \mathrm{torr}$ ) during the recovery period resulted in significantly worse experimental retinopath (16). Herein. we performed two additional tests of recovery period oxygenation. In study A we asked whether variable hypoxemia and hyperoxia, as might be experienced during an unstable prematures convaleseence. would result in a worsening of the retinopathy. In study $B$ we examined the hypothesis first suggested by Srewersk (17) and 
Bedrossian et al. $(18,19)$ that gradually withdrawing oxygen after an oxygen-induced injury would lessen the severity of the subsequently observed retinopathy.

\section{METHODS}

Kittens from a chronically maintained colony of mixed breed cats were used. The pregnant queens were separated from the colony when palpation revealed they were pregnant, and their dry cat food was supplemented with a wet cat food and vitamin and iron mixture (Visinerol) throughout the remainder of the pregnancy and lactation. The queens were observed daily, and the day kittens were discovered was defined as day 1 . On day 3 , the queen and her kittens were placed in an infant incubator (Air Shield Isolette, Hatboro, PA) at $27^{\circ} \mathrm{C}$ with the oxygen concentration adjusted to $80 \pm 1 \%$. The kittens were given identification numbers at birth, and after $65 \mathrm{~h}$, half of each litter was randomly selected (by drawing numbered cards from a box) to return to room air for recovery or to remain in the incubator. The flow rate for the various gases exceeded 10 liters/min and no accumulation of carbon dioxide occurred (measurement with an infrared analyzer, carbon dioxide concentration $=<0.05 \%)$.

In study $\mathrm{A}$, variable oxygen recovery, 16 litters ( 33 room air recovery kittens and 37 variable oxygen recovery), the incubator was subsequently connected to three gas sources ( $100 \%$ oxygen, $100 \%$ nitrogen, and $21 \%$ oxygen) that were cycled at 6 -min intervals by an automatic clock (Fig. 1). The oxygen concentration was recorded several times a day with a Beckman paramagnetic oxygen analyzer, and on at least two or three occasions for each litter in the variable study, oxygen was monitored continuously for a period of $1-2 \mathrm{~h}$ to document the swings being achieved in that particular incubator for that particular experiment. The inset in Figure 1 shows a segment of one of those monitoring periods and is typical of the rest. Maximum oxygen concentration ranged from 37 to $43 \%$ and the minimum oxygen ranged from 8 to $11 \%$. Using a continuous trans-conjunctival tissue oxygen monitor, tissue oxygen was monitored noninvasively for a 2 -h period in one 7-day-old kitten during exposure in the variable oxygen incubator in order to estimate the rate of change in oxygenation at the tissue level (Orange Medical Instruments, Costa Mesa, CA).

In study B, gradual withdrawal of oxygen, 15 litters ( 26 gradually withdrawn kittens and 25 room air recovery), the oxygen concentration in the incubator was initially dropped to $70 \%$ for $1 \mathrm{~h}, 60 \%$ for $1 \mathrm{~h}$, and then to $50 \%$ oxygen. Thereafter it was lowered 3 to $1 \%$ per day as shown in Figure 2. The recovery phase continued until $28 \pm 2$ days of age when the kittens were sacrificed, the vasculature perfused with india ink, and retinal flat mounts prepared as previously described (20). The permanently mounted retinae were coded and mixed so that the two investigators could score them without knowledge of the treatment used or of each others scores. The four subcategories of the retinopathy are scored separately, the total permitting a worst or maximal score of 13 and a normal score of 0 to 1 (16). Subcategory $\mathrm{A}$ measures the extent of vascularization of the retina, subcategory $\mathrm{B}$ the number and pattern of retinal vessels, subcategory $C$ the loss of periarteriolar capillary free zone, and subcategory $\mathrm{D}$ the amount of extraretinal neovascularization. The retinae were scored using a binocular dissecting microscope, and if the total score assigned to a particular retina by the two investigators differed by more than two points, the retina was recoded and mixed in with a subsequent box for repeat scoring. The final score for each kitten was the arithmetic mean of four scores (right and left eyes as scored by each of two investigators). There were two final scores for each litter (the average of the room air kitten scores and the average of the experimental oxygenation recovery kitten scores) and these were the ones used for data analysis.

Sample sizes were based on our prior experience with this model $(16,20)$. The predicted retinopathy scores following room air recovery to $4 \mathrm{wk}$ after $65 \mathrm{~h}$ of $80 \%$ oxygen started on day 3 were $5.3 \pm 2.5$ (mean $\pm \mathrm{SD}$ ) (16). Assuming that we wished to be $80 \%$ certain (type II error $=0.20$ ) that we would detect a difference of at least 2 points in the retinal score (type I error = 0.05 , two-tailed paired $t$ test), just over 15 litters would be needed. Therefore, 16 litters were used to test each hypothesis (although one litter was stillborn in study B). The paired $t$ test was chosen to enhance comparison of experimental to control kittens in the same litter because of the known litter to litter variability in room air recovered retinal scores. Although a $t$ test is not usually applied to data which have upper and lower boundaries, the experimental retinopathy scores fell in the midzone of the scoring system and were approximately normally distributed, making its use reasonable in this case.

\section{RESULTS}

Study A: variable oxygen recovery study. The kittens tolerated the hyperoxia and variable recovery conditions well without mortality and grew equally well in both environments (weight at

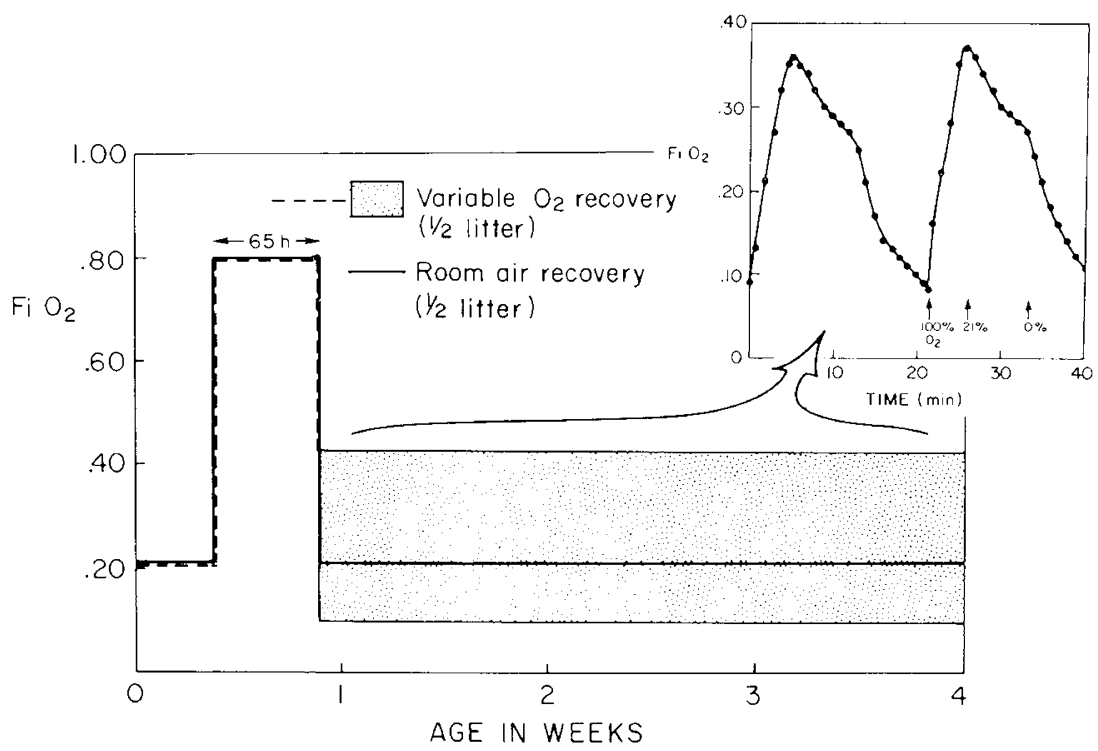

Fig. 1. Variable oxygen recovery study design: the time course over 4 wk for each litter is shown. The inset shows an expansion of the stippled area over several minutes for the variable oxygen concentration, as controlled in the infant incubator throughout the recovery time period. After the initial 65 -h exposure to $80 \%$ oxygen, half of each litter recovered in room air and half in the incubator with the variable oxygenation. 


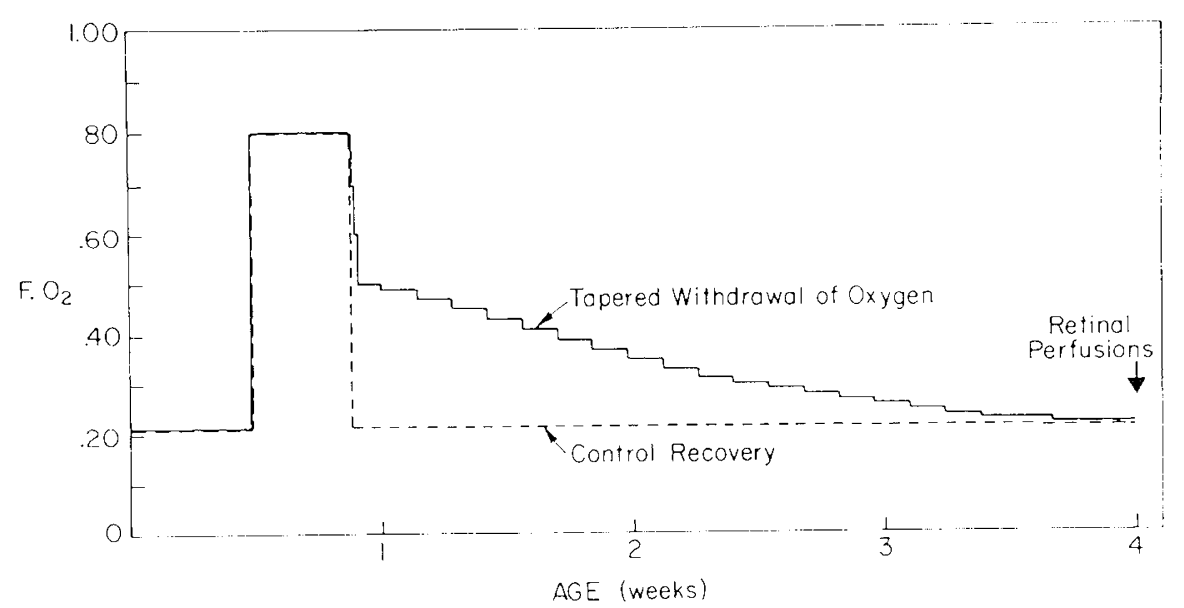

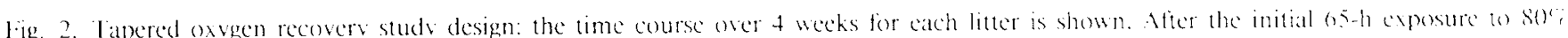
oxygen, half of each litter recovered in room ar (des/hed line) and the other half in the incubator with a gradually tapered oxygen concentration (solid line').

4 wh. 330 $\pm 70 \mathrm{~g}$ in room air verses $314 \pm 82 \mathrm{~g}$ in variable oxygen, mean + SI) ). Thirty-three kittens recovered in room air and 37 in the variable oxygen incubators.

The retinopathy results were the opposite of what had been predicted. Figure 3 shows the mean and SFM for the total retinopathy seores and the subeategory seores from each litter. The kittens in the variable oxygenation recovery group had lower (better) retinopathy soores than their littermates (pared / cest. p) $<0$ (0)1). This was also true when each of the four subeategories was examined separately. Table 1 shows the mean and Si) of the pared differences hetween the room air kittens and their variable oxygenation recovered fittermates.

In ou previously reported sudy of continuously hypoxemic recover: we noted that retinal and/or vitreal hemorrhages were found more fiequenty in kitkens who recovered in a hypoxemic enviromment than in their litlermates who recovered in room ais (16). In the present study, retinal hemorthage occurred in 14 , 66. or $21 \%$ of room air recovered retinac and in 7/74. or 9 \% of variable oxygen recovered retinae (reported as number of eyes rather than number of kitcens, $p<0.10$. $x$ lest with Vates correction).

Results of the conjunctival tissue oxygenation monitoring are shown in ligure 4 and demomstrate that the rate of change in tissuc oxygen levels closely reflected the rate of change in inspired oxygen, but that true tissue hypoxia was probably unlikely to have occurred since the transeonjunctival $p()$, never fell below 18 torr, at least in this particular kitten. In additional monitoring not shown. Whe mean transconjunctival PaO, was shown to rise to $119 \pm 9$ lom in contintous $80 \%$ oxygen and fell to $15 \pm 1$ torr in continuous $13 \%$ oxygen. Fransconjunctival $\mathrm{p}$ ), in room air was $53 \pm 8$ torr (all moan $\pm S D$ )

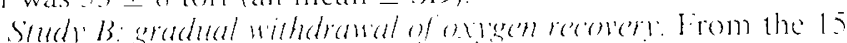
remaining liters, 25 kittens recovered in room air and 26 in the gradually withdrawn oxygen recovery incubators. The kitlens in room air grew slightly hetter (weights at 4 wh. $394 \pm 72$ g in room air lerws $3.32 \pm 85 g$ in lapered oxygen. mean \pm SI $) . p<$ 0.02. Student's/ test). The total experimental retimopathy scores are shown graphically on the far righ in Iigure 5. There were no significant differences between the total scores or any of the four subeategories (not shown) when analyed hy the pared 1 test. which tested the differences between paired litermates (Table 2). Retinal hemorrhages were also uncommon and did not significantly differ between the room air recovery $(1 / 50$. $2 \%$ of eyes) and gradually withdrawn oxygen recovery kitlens $(6 / 52$. $12 \%$ of eyes).

\section{I)ISC (ISSIO)}

These unexpected results ked first to a testing of the model's reproducibility. The retinopathy scores from the control kittens

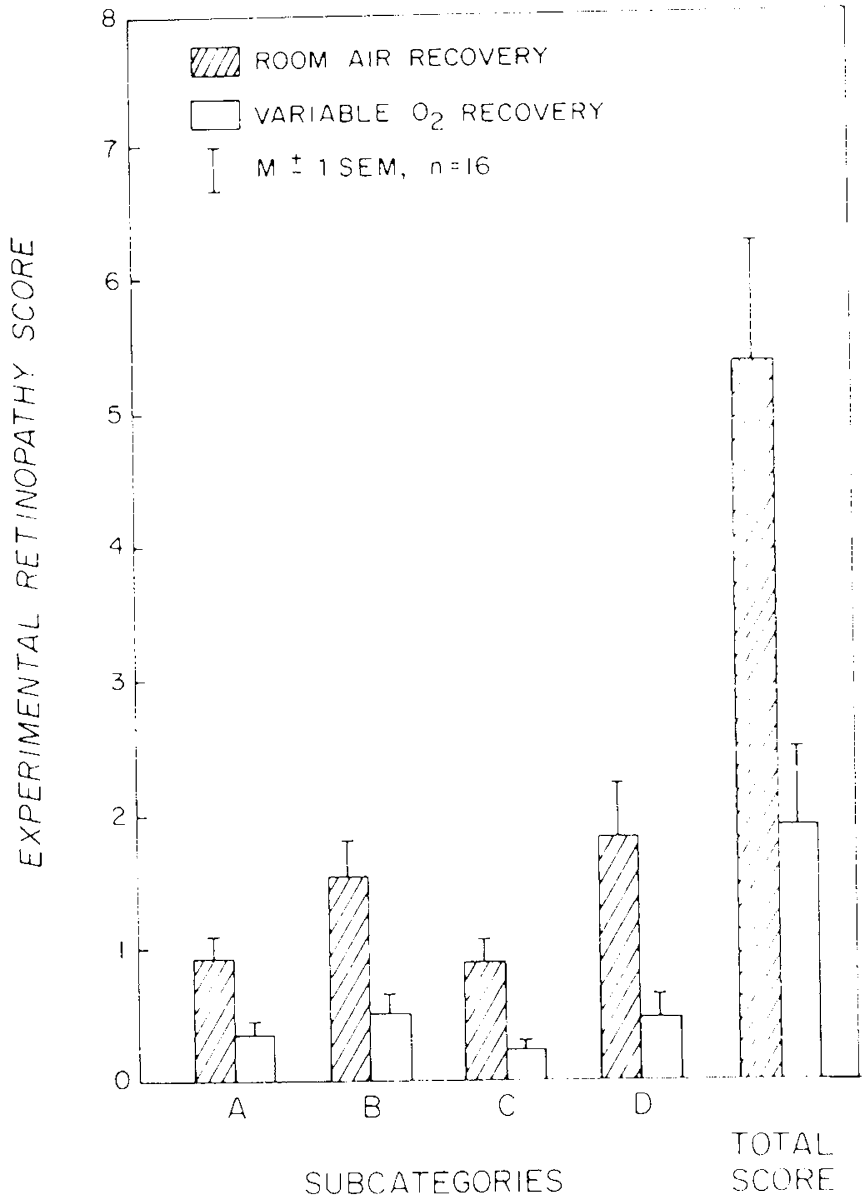

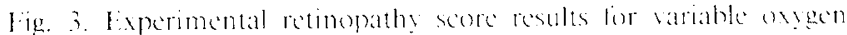

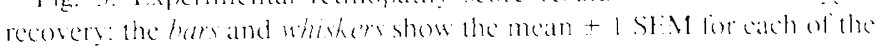
four subategortes of the scoring ssstem and the total score. 1 if since all room ar recosery hittens from one liter were averaged as a single value for that litter and all kittens from the variable group from one litter were averaged for a single value in the same litter. The ementhethed

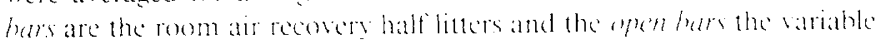
()xygen recosery hall litters.

in studies $A$ and $B$, ic room ait recosery atter 65 h al 80 \% oxygen, were companed to previously published expericonec with this model and were found to fall where expeced (2) the rom air recovery scores were eompared to the room ait recoser? controls from the out previously reported study of hyposic 
Table 1. Experimental retinopathy scores*_variable oxygenation recovery $\dagger$

\begin{tabular}{cccccc}
\cline { 3 - 6 } Score component & $\mathrm{A}$ & $\mathrm{B}$ & $\mathrm{C}$ & $\mathrm{D}$ & Total \\
\hline Mean difference* & 0.55 & 0.98 & 0.62 & 1.34 & 3.57 \\
SD of differences & 0.62 & 1.02 & 0.66 & 1.40 & 3.55 \\
\hline
\end{tabular}

* The mean difference is the average of each of the differences for the 16 litters. Each individual litter difference is the average of the variable oxygen recovery scores from the one to three kittens in one litter subtracted from the average of the one to three room air recovery kittens from the same litter.

$\dagger p$ value $<0.01$ for all (paired $t$ test).

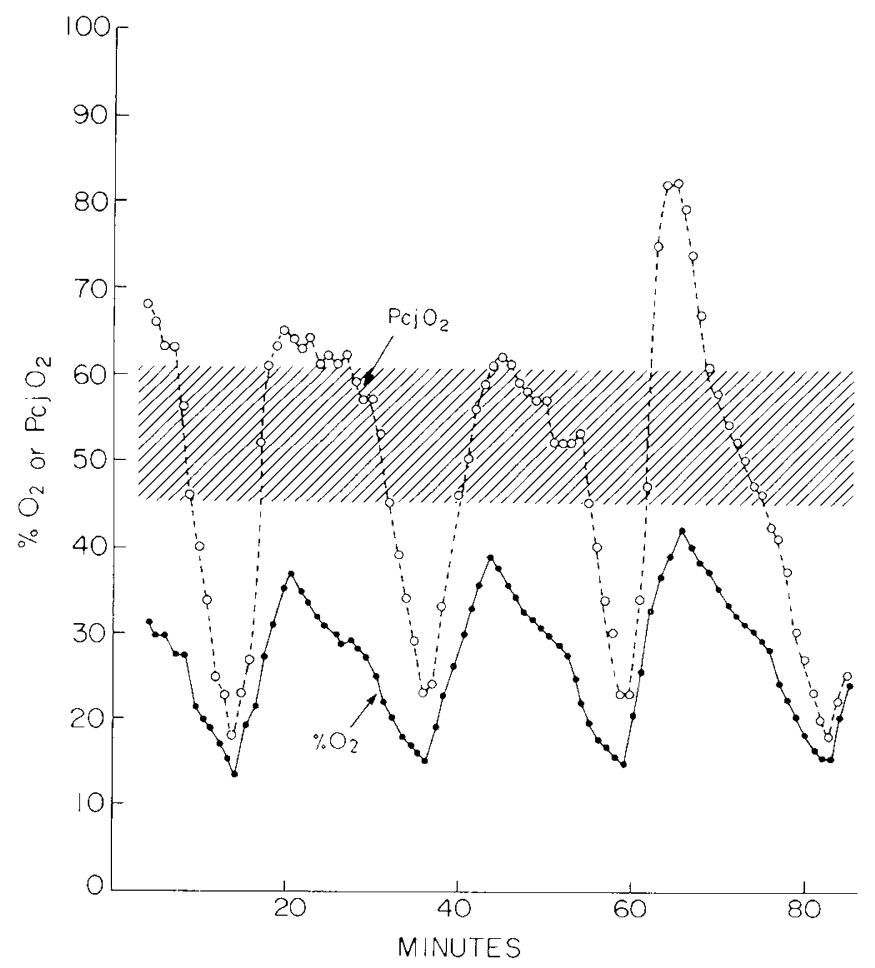

Fig. 4. Transconjunctival oxygen: transconjunctival partial pressure of oxygen and simultaneous inspired oxygen in one kitten over $80 \mathrm{~min}$. The inspired oxygen is shown with closed circles connected by the solid line and transconjunctival $\mathrm{pO}_{2}\left(\mathrm{PcjO}_{2}\right)$ with open circles connected by a dashed line. The shaded area shows the mean $\pm 1 \mathrm{SD}$ for the $\mathrm{PcjO}_{2}$ in room air.

recovery (16). Figure 5 shows graphically that the room air recovery kittens from the reported study and the two current studies (shaded bars) have mean scores that do not differ from one another. These results confirm the reproducibility of this model.

The experimental results serve to make an important point: that the oxygenation status during recovery following an oxygeninduced injury to the developing retinal vasculature in the kitten does affect its healing process and the resultant retinopathy. These findings support the preliminary findings of Bedrossian et al. $(18,19)$ who found that the methods of withdrawal of oxygen from premature infants affected the incidence of ROP. Our findings also support the clinical impressions of Szewczyk (17) that late pulmonary disease in infants, such as pneumonia, might precipitate or worsen ROP. We do not understand the degree to which this can occur, nor its mechanism, but it is a potentially important and as yet unappreciated factor in ROP.

The shape of the inspired oxygen level curve during the variable oxygenation study was reflected quite closely in time at the tissue level, as measured by a transconjunctival tissue electrode. The magnitude of the changes, however, were blunted and it is

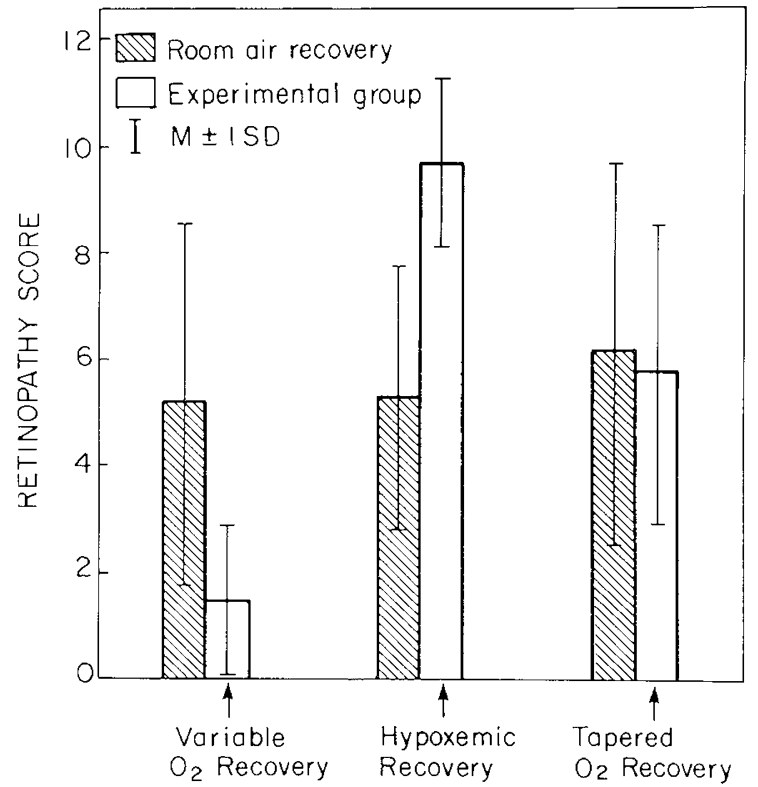

Fig. 5. Comparison of the outcomes of three trials of recovery oxygenation following a $65-\mathrm{h} 80 \%$ oxygen-induced retinopathy in the kitten. The bars and whiskers show the mean, $\pm 1 \mathrm{SD}$ of the average scores for each litter within a study group. The cross-hatched bars represent the room air recovery half litters and the open bars represent the experimental condition recovery half litters. Results from the hypoxemic recovery group have been previously published (16).

Table 2. Experimental retinopathy scores*_Gradual Withdrawal of Oxygenation Recovery†

\begin{tabular}{lrrrrl}
\hline Score component & \multicolumn{1}{c}{ A } & \multicolumn{1}{c}{ B } & \multicolumn{1}{c}{ C } & D & Total \\
\hline Mean difference* & -0.20 & 0.01 & -0.02 & 0.58 & 0.40 \\
SD of differences & 0.98 & 1.54 & 0.79 & 1.65 & 4.85 \\
\hline
\end{tabular}

* The mean difference is the average of each of the differences for the 15 litters. Each individual litter difference is the average of the gradually withdrawn oxygen recovery scores from the one to three kittens in one litter subtracted from the average of the one to three room air recovery kittens from the same litter.

$\dagger p$ value for all $>0.10$ (paired $t$ test), power $>80 \%$.

not clear whether the tissues experienced a net effect of hypoxemia or hyperoxia. Study A however, shows that repeated, relatively short periods of elevated $\mathrm{pO}_{2}$ (less than $6 \mathrm{~min}$ ) do not worsen an existing oxygen-induced retinopathy in this model. If the inspired oxygen level curve is mathematically averaged, it can be seen that the kittens in study $\mathrm{A}$ experienced an average inspired oxygen level of $28 \%, 7 \%$ above room air. A possible explanation of our findings may be that this mildly elevated oxygen level during a recovery period was beneficial. This hypothesis is being investigated in the kitten model and if positive might justify clinical testing.

It must be remembered, however, that the kitten oxygeninduced retinopathy model has serious limitations when attempting to extrapolate these data to clinical trials. Outstanding is that the retina in the kitten does not develop a thickened ridge of new tissue within the retinal substance, nor does there seem to be associated myofibroblast proliferation into the vitreous, although the kitten does experience extensive vessel growth into the vitreous (21). Also although both Ashton et al. (22) and Patz et al. (23) initially reported that retinal detachments did occur in the kitten model, this has not proven to be true in repeated attempts to elicit full blown ROP in kittens (21) (Phelps DL, Rosenbaum $\mathrm{AL}$, unpublished data; Patz A, personal communication). Although it would seem reasonable that conditions resulting in a less severe oxygen induced retinopathy in this model could interpolate to less severe ROP in humans, any promising theory 
must be cautiously tested in clinical trials before receiving widespread application.

Work by Kreter and Hittner (24) suggests that an active angiogenesis factor is produced by the avascular retina to induce vessel growth. and their hypothesis is that it is produced by endothelial precursor cells, called spindle cells. that have been damaged by oxvgen. Our findings are compatible with this hypothesis in that various oxygenation levels could well influence or control such an angiogenic factor. or the cells producing it. An additional potential drawback of the kitten model in light of the Kretzer hypothesis is that spindle cells are sparse or absent in the feline avascular retina $(21,24)$. On the other hand. it is clear that the kitten. like other mammalian species studied. produces a retinal derived angiogenic factor (25) and this factor is subject to a regulatory effect from oxygen (26).

There is strong evidence in the kitten model of oxygen-induced retinopathy that oxygenation status influences the course of healing. Chronic hypoxia impairs the healing whereas variable oxygenation leads to improved healing. possibly through an overall moderate increase in oxygen delivery to the injured retina. These findings may justify cautious controlled trials of increased oxygenation in infants with significant ROP.

Acknowledgrnemt. The authors recognize the dedicated work of Zeno Turner on this project.

\section{RIFIRINVCIS}

1. Mccormick $A Q 1977$ Retinopathy of prematurity. (urr Probl Pediatr 7:1128

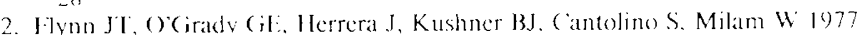
Retrolental fibroplasia. I. (linical ohservations. Arch Ophthalmol 95:217223

3. Kingham JI) 1977 Acute retrolental fibroplasia. Arch Ophthalmol 95:39-47

4. Manros: B. Wright W, Browne R 1979 Risk factors for retinopathy of prematurity. Pediatr Res 13:500)(ahstr)

5 Kinsey $V_{1}$ : Arnolo HIJ Katina RE Stern I. Stahlman M. Odell (i. I)riscoll JM, I:lliott JH, Payne J. Patz A 1977 PaO 2 kevels and retrolental fibroplasia: A report of the cooperative study. Pediatrics $60: 6555-60,8$

6. (iunn IR, Easdown J. Outerbridge I:W. Aranda JV 1980) Risk factors in retrolental fibroplasia. Pediatrics $65: 1096-1100$

7. Shahinian I. Jr, Malachowski N 1978 Retrolental fibroplasia: a now analysis of risk factors based on recent cases. Arch Ophthalmol 96:7()-74

8. Bauer ( $\mathrm{R} 1978$ The occurrence of retrolental fibroplasia in infants of birth

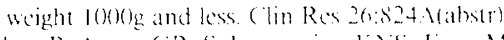

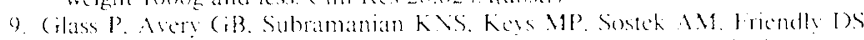
1985 1 ffece of brighe light in the hospital nursers on the incidence of

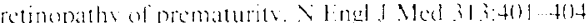

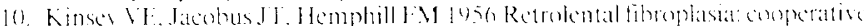

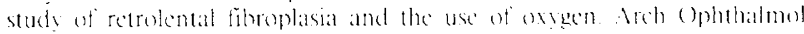
$50: 481-347$

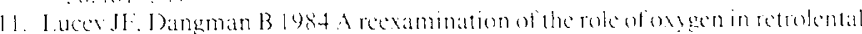
tibroplasia. Pediatries $73: 82 \ldots 96$

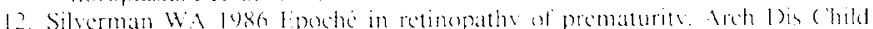
$61: 525-525$

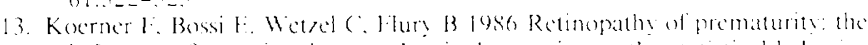
influence of gestational age and retinal maturity on the statistical hehastor of risk factors (jractes Arch (lin fixp) (Ophthatmol 2.24:40-.45

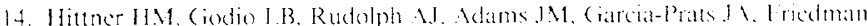

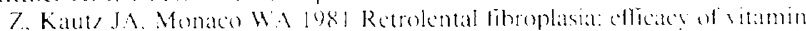

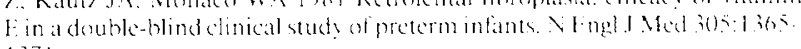
1371

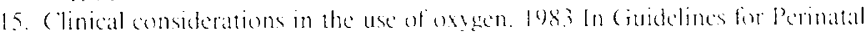
care American Academs of Pediatrics. American (ollege of ( )hesetricians and (isnecologists. Washington $\mathrm{I})(\mathrm{pp} 212-216$

16. Phelps DI. Rosenbaum a ligst fiffects of margmal hypoxemia an recoseds from oxygen-induced retinopathy in the kitten model. Pediatries $7: 30$

17. Syewerk is 1953 Retrolental Fibroplasia and related ocular discases. ('assification ctiology and prophylaxis am J ()phthatmol $36: 1333-1,301$

18. Bedrossian RII. (armichael P. Ritter JA lys5 fotfect of oxygen weaning in Retrolental fibroplasia. Arch Ophathatmol $53.514-518$

19. Bedrossian RH. (armichacl P. Ritter J 1954 Retinopathy of prematurity (Retrolental Fibroglasia) and oxvgen: part I. (lincal sudv: part ll. l urther observations on the discase. Am I ()phthalmol $37: 78$-.86

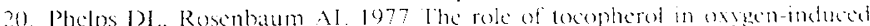
retinopathy: Kitten moded. Pediatrics Sy(suppla:908 $1(0) 5$

21. (iole (i. Animal models of retinopathy of prematurity in silverman wA Flynn $J T$ (eds) (ontemporary Issues in Fetal and Veonatal Medicine : Retinomathy of Prematurity. Blachwell Scientific Pubtications. Buston. pp $53-95$

22. Ashton $\mathrm{V}$. Ward B. Serpell (; 1953 Role of oxygen in the gencesis of retrolental libroplasia. A preliminary report. Br .J Ophthalmol $37,51,3-520$

23. Patr A. Fastham A. Heginbotham DH. Klch ] 1953 (Oxgen studes in retolental fibroplasia It. The production of the microscopic changes of retrolental fibroplasia in experimental animals am I ()phthal $36: 151-1522$

24. Kretzer 11 . Hittner HM 1985 Intiating events in the develogment of eting athy of prematurity. In: Silverman W. A. Jynn J T (eds) (ontemporars lssues in Fetal and Veonatal Medicine 2: Retinopathy of Prematurity. Blackwell Scientific Publications. Boston. p) 121-152

25 (ilaser BM D'Amore PA. Michels R(;. Pate A. Fensetau A 1980 Demonstrat tion of vasoproliferative activity from mammalian retina. I (c)ll Biol \$ $84: 298$ 3() 4

26. Faylor ( M. Weiss JB. Kissun RD). ( iamer A 1986 1:ffect of oxygen tension on the quantitics of procolligemase-activating angiogenic fiactor presem in the developing kitten retina. Br J Ophthat 70:162-16.5 